\title{
Evaluation of trophic parameters in newly built reservoir using canonical variates analysis
}

\author{
Dariusz Kayzer ${ }^{1, *}$, Przemystaw Frankowski ${ }^{2}$, Janina Zbierska ${ }^{3}$, and Ryszard Staniszewski ${ }^{3}$ \\ ${ }^{1}$ Department of Mathematical and Statistical Methods, Poznań University of Life Sciences, Wojska Polskiego 28, 60-637 Poznań, \\ Poland \\ ${ }^{2}$ Afirma Ltd., Wojnowo, 62-095 Murowana Goślina, Poland \\ ${ }^{3}$ Department of Ecology and Environmental Protection, Poznań University of Life Sciences, Piątkowska 94C, 60-649 Poznań, Poland
}

\begin{abstract}
Wielkopolska region has precipitation below country average and water shortage is especially visible during spring and summer, thus regeneration of water bodies play important role in saving of water reserves in rural areas. The newly built water reservoir is located in Nienawiszcz, Rogoźno commune, Poland. The aim of study was to compare experimental sites according to parameters describing water trophy like chlorophyll $a$, dry mass of seston, total organic carbon, biochemical oxygen demand and according to concentrations of nitrogen and phosphorus compounds. Sites were compared using location in reservoir and year season. In the year 2014 (after connection of both parts of lake) part A and B of reservoir had similar trophic conditions, thus confirming stabilisation of the reservoir as an initial freshwater ecosystem. Water table level was also stable, thus low average water depth was not affected water quality Based on canonical variates analysis it was showed, that changes of nitrates and total nitrogen concentrations strongly affected the variability of experimental objects in comparison to concentrations of nitrites and total phosphorus. In the year 2014, after connection of both parts A and B the reservoir start to stabilise in case of similarity of water quality parameters in surveyed sites.
\end{abstract}

\section{Introduction}

Wielkopolska region characterised with water shortage in agriculture, low precipitation and inconvenient timetable of rainfalls. Improving of sustainability of surface waters volume need actions undertaken in watersheds, as like as maintenance of small retention [1]. It is related to water management strategies in municipalities and in watershed aspects [2-3]. Sustainable development of water management is perceived as activities concerning economic, social and ecological aspects, thus enhance successful implementation of this idea [4-5]. Rebuilt and recultivation of small water reservoirs in rural landscape is an answer for the needs of Water Framework Directive [6]. Aquatic ecosystems are effective measure to limiting migration of biogens to waters and to soil profiles and increase water resources in watershed [7]. According to information from the Project of counteraction against consequences of drought in upper Vistula water region [8] increasing of retention in agricultural areas using regeneration of midfield ponds and other small water bodies would give positive results in relatively short time. Such a activities are positive and necessary in watersheds. Regeneration of water bodies have impact on biodiversity in improvement of water quality in certain area.

When water reservoir is planned in the place of postmining activities it is possible to figure out the pit dimensions to facilitate further works and prepare area around water for other operations. Additionally, exploitation should be undertaken with respect to environment not only with income in investor's mind [9].

Reassuming, it is possible to decrease the rate of disappearing of water reservoirs in rural landscape by means of recultivation and rebuilt of water bodies and land management activities should focused on such a projects especially in areas with shortage as in Wielkopolska [10-11].

\section{Study area}

Studied water reservoir was built in years 20042012, by means of peat excavation and economic use of this raw material. After exploitation of the peat deposit subsequent reclamations were carried out to establish shape of body with banks. This newly built reservoir is located in agricultural and forest landscape with 
significant slopes and relative heights. Part of watershed is covered by grasslands. There are also small areas of forest, afforestations and bushes. On western side there is a forest area administrated by Łopuchówko Forestry Management. Restored lake, which was there in ancient times has actual area of 11 ha, average depth of $1.64 \mathrm{~m}$, maximum depth of $3.20 \mathrm{~m}$ and its postglacial slopes are broad shoreline are the same as several thousand years ago [12].

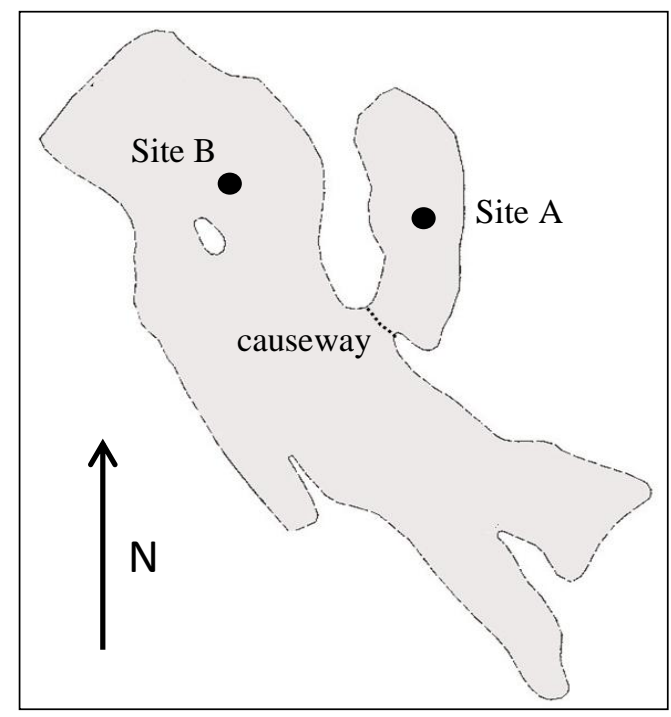

Fig. 1. Sketch map of reservoir and survey sites.

\section{Material and methods}

Water samples for evaluation of chemical parameters were collected four times per year from surface layer and they were representing year seasons. Samples were collected in sites A and B and showed in Figure 1 in the years 2012 and years 2013-2014 when reservoir was one ecosystem after connection of two parts A and B by removing of causeway (summer 2012). Number of samples from part A was higher because this part of reservoir was flooded several years earlier. Samples were stored in ice box and analyses were made within 24 hours. Water samples for nitrates, nitrites and ammonium were filtered using $0.45 \mu \mathrm{m}$ size pore, samples for total phosphorus and total organic carbon were not filtered. Following analyses were done by certified laboratory of Aquanet SA Poznań:

- nitrates $\left[\mathrm{mg} \mathrm{NO}_{3} \cdot \mathrm{dm}^{-3}\right.$ ] - PN-EN ISO 10304-1:2009,

- nitrites $\left[\mathrm{mg} \mathrm{NO}_{2} \cdot \mathrm{dm}^{-3}\right]$ - PN-EN 26777:1999,

- ammonium $\left[\mathrm{mg} \mathrm{NH}_{4} \cdot \mathrm{dm}^{-3}\right.$ ] - PN-ISO 7150-1:2002,

- total phosphorus $\left[\mathrm{mg} \mathrm{P} \cdot \mathrm{dm}^{-3}\right]-\mathrm{PN}-\mathrm{EN}$ ISO 172942:2006

- total nitrogen $\left[\mathrm{mg} \mathrm{N} \cdot \mathrm{dm}^{-3}\right]$ - PN-EN 25663:2001, PB/PFO-26, 01.02.2011,

- total organic carbon (TOC) $\left[\mathrm{mg} \mathrm{C} \cdot \mathrm{dm}^{-3}\right]-\mathrm{PN}-\mathrm{EN}$ 1484:1999,

- dry mass of seston $\left[\mathrm{mg} \cdot \mathrm{dm}^{-3}\right]-\mathrm{PB} / \mathrm{PCh}-15$, 07.02.2007 and PB/PCh-15, 01.02.2011,

- chlorophyll $a\left[\mu \mathrm{g} \cdot \mathrm{dm}^{-3}\right]$ - PN-86/C-05560/02,

- biochemical oxygen demand $\left(\mathrm{BOD}_{5}\right)\left[\mathrm{mg} \mathrm{O} \mathrm{O}_{2} \cdot \mathrm{dm}^{-3}\right]-$ PN-EN 1899-1:2002 and PN-EN 1899-2:2002.
To study of the relationship between trophic parameters and parts of reservoir, tools of multidimensional analysis were used. Let us assume the structure of a model for $k^{\text {th }}$ trophic parameter $y_{i j}(k)$ coming from the $i^{\text {th }}$ experimental object $(i=1, . ., I$; here $I=5)$ and the $j^{\text {th }}$ measuring series $(j=1, \ldots, J$; here $J=$ 4):

$$
y_{i j}(k)=\mu(k)+\alpha_{i}(k)+\beta_{j}(k)+e_{i j}(k)
$$

where for $k^{\text {th }}$ trophic parameter $(k=1, \ldots, K$; here $K=4)$ :

$\mu(k)$ presents general mean values,

$\alpha_{i}(k)$ is the effect of $i^{\text {th }}$ experimental object,

$\beta_{j}(k)$ is the effect of $j^{\text {th }}$ measuring series,

$e_{i j}(k)$ is the error related with combination of $i^{\text {th }}$ object and $j^{\text {th }}$ series.

In this case, the experimental object was defined as the trophic parameter values for part A or B of reservoir in the individual year. Due to correlations between trophic parameters it was sufficient to use tools of multivariate analysis for determination the differences between experimental object and series. Hence, the considered model (1) for one experimental object and one measuring series can be presented in the form:

$$
\mathbf{y}_{i j}=\boldsymbol{\mu}+\boldsymbol{\alpha}_{i}+\boldsymbol{\beta}_{j}+\mathbf{u}_{i j}
$$

where $\mathbf{y}_{i j}=\left[y_{i j}(1), \ldots, y_{i j}(K)\right]^{\prime} ; \boldsymbol{\mu}=[\mu(1), \ldots, \mu(K)]^{\prime}$; $\boldsymbol{\alpha}_{i}=\left[\alpha_{i}(1), \ldots, \alpha_{i}(K)\right]^{\prime} ; \quad \boldsymbol{\beta}_{j}=\left[\beta_{j}(1), \ldots, \beta_{j}(K)\right]^{\prime} ;$ $\mathbf{u}_{i j}=\left[e_{i j}(1), \ldots, e_{i j}(K)\right]^{\prime}$.

The model (2) can be describe in the matrix form:

$$
\mathbf{Y}=\mathbf{1}_{N} \boldsymbol{\mu}^{\prime}+\mathbf{X}_{1} \boldsymbol{\alpha}+\mathbf{X}_{2} \boldsymbol{\beta}+\mathbf{U}
$$

where $\mathbf{Y}=\left[\mathbf{y}_{11}, \ldots, \mathbf{y}_{1 J}, \mathbf{y}_{21}, \ldots, \mathbf{y}_{I J}\right]^{\prime} ; \boldsymbol{\alpha}=\left[\boldsymbol{\alpha}_{1}, \ldots, \boldsymbol{\alpha}_{I}\right]^{\prime}$; $\boldsymbol{\beta}=\left[\boldsymbol{\beta}_{1}, \ldots, \boldsymbol{\beta}_{J}\right]^{\prime} ; \quad \mathbf{U}=\left[\mathbf{u}_{11}, \ldots, \mathbf{u}_{1 J}, \mathbf{u}_{21}, \ldots, \mathbf{u}_{I J}\right]^{\prime} ;$ $\mathbf{X}_{1}=\mathbf{I}_{I} \otimes \mathbf{1}_{J} ; \mathbf{X}_{2}=\mathbf{1}_{I} \otimes \mathbf{I}_{J}$ (the symbol $\otimes$ denote the Kronecker product of matrices).

Finally the considered model (3) can be presented in the form:

$$
\mathbf{Y}=\mathbf{X} \mathbf{\Xi}+\mathbf{U}
$$

where $X=\left[\mathbf{1}_{N}: \mathbf{X}_{1}: \mathbf{X}_{\mathbf{2}}\right]$ and $\Xi^{\prime}=\left[\boldsymbol{\mu} \vdots \boldsymbol{\alpha}^{\prime} \vdots \boldsymbol{\beta}^{\prime}\right]$.

Two matrices were analyzed: $\mathbf{C}_{\mathbf{1}} \boldsymbol{\Xi}_{1}, \mathbf{C}_{\mathbf{2}} \boldsymbol{\Xi}_{\mathbf{2}}$ where $\mathbf{C}_{1}=I_{I}-\frac{1}{I} \mathbf{1}_{I} \mathbf{1}_{I}^{\prime}, \mathbf{C}_{2}=I_{J}-\frac{1}{J} \mathbf{1}_{J} \mathbf{1}_{J}^{\prime}$ and the matrix $\boldsymbol{\Xi}_{1}$ and $\boldsymbol{\Xi}_{\mathbf{2}}$ can be wrriten as follows $\boldsymbol{\Xi}_{\mathbf{1}}=\left(\mathbf{X}_{\mathbf{1}}^{\prime} \mathbf{X}_{\mathbf{1}}\right)^{-\mathbf{1}} \mathbf{X}_{\mathbf{1}}^{\prime} \mathbf{Y}$ and $\boldsymbol{\Xi}_{\mathbf{2}}=\left(\mathbf{X}_{\mathbf{2}}^{\prime} \mathbf{X}_{\mathbf{2}}\right)^{-\mathbf{1}} \mathbf{X}_{\mathbf{2}}^{\prime} \mathbf{Y}$. The elements of the matrix $\mathbf{C}_{\mathbf{1}} \boldsymbol{\Xi}_{\mathbf{1}}$ are differences in trophic parameters between the means of individual experimental object and the mean values of all objects. Similarly, the elements of the matrix $\mathbf{C}_{2} \mathbf{\Xi}_{\mathbf{2}}$ are differences in trophic parameters between measuring series and the mean value of all series.

The analyses performed to determine the relationship between trophic parameters made it possible to present the position of selected experimental objects in the space of the two first canonical variates [13]. The method of canonical variate analysis (CVA), similar to principal component analysis, was chosen because considering data sets coming from the multidimensional experimental linear model classified according to two sources of variability. In the case of our investigations on the differences between experimental objects, this method consists in transforming the matrix $\mathbf{C}_{1} \boldsymbol{\Xi}_{1}$ into a set of new variables, which carry similar information, but are distributed in a multivariate Euclidean space [13-15]. 
Following the transformation, the matrix $\mathbf{C}_{1} \mathbf{\Xi}_{1}$ is presented in the form:

$$
\mathbf{C}_{1} \boldsymbol{\Xi}_{1}=\sum_{h=1}^{a} \lambda_{1 h}^{-1 / 2} \boldsymbol{\Psi}_{1 h} \boldsymbol{\varphi}_{1 h}^{\prime},
$$

where $a=\min (K, I-1)$ and the vectors $\boldsymbol{\Psi}_{1 h}, \boldsymbol{\varphi}_{1 h}$ and scalars $\lambda_{1 h}$ are determined from equations of the form:

$$
\mathbf{C}_{1} \Xi_{1} \mathbf{S}^{-1}\left(\mathbf{C}_{1} \Xi_{1}\right)^{\prime}\left[\mathbf{C}_{1}\left(\mathbf{X}_{1}^{\prime} \mathbf{X}_{1}\right)^{-1} \mathbf{C}_{1}^{\prime}\right]^{-} \boldsymbol{\Psi}_{1 h}=\lambda_{1 h} \boldsymbol{\Psi}_{1 h},
$$

$\left(\mathbf{C}_{1} \boldsymbol{\Xi}_{1}\right)^{\prime}\left[\mathbf{C}_{1}\left(\mathbf{X}_{1}^{\prime} \mathbf{X}_{1}\right)^{-1} \mathbf{C}_{1}^{\prime}\right]^{-} \mathbf{C}_{1} \boldsymbol{\Xi}_{1} \mathbf{S}^{-1} \boldsymbol{\varphi}_{1 h}=\lambda_{1 h} \boldsymbol{\varphi}_{1 h}$

where $\mathbf{S}=\frac{1}{N-r} \mathbf{Y}^{\prime}\left(\mathbf{I}_{N}-\mathbf{X}\left(\mathbf{X}^{\prime} \mathbf{X}\right)^{-} \mathbf{X}^{\prime}\right) \mathbf{Y}(r=I+J-1$ is the order of matrix $\mathbf{X})$. The vectors $\boldsymbol{\Psi}_{1 h}$ and $\boldsymbol{\varphi}_{1 h}$ are standardised in the following way:

$$
\begin{aligned}
& \boldsymbol{\Psi}_{1 h}^{\prime}\left[\mathbf{C}_{1}\left(\mathbf{X}_{1}^{\prime} \mathbf{X}_{1}\right)^{-1} \mathbf{C}_{1}^{\prime}\right]^{-} \boldsymbol{\Psi}_{1 h^{\prime}}=\left\{\begin{array}{ccc}
\lambda_{1 h}, & \text { if } & h=h^{\prime} \\
0, & \text { if } & h \neq h^{\prime}
\end{array},\right. \\
& \boldsymbol{\varphi}_{1 h}^{\prime} \mathbf{S}^{-1} \boldsymbol{\varphi}_{1 h^{\prime}}=\left\{\begin{array}{ccc}
\lambda_{1 h}, & \text { if } & h=h^{\prime} \\
0, & \text { if } & h \neq h^{\prime}
\end{array} .\right.
\end{aligned}
$$

The vectors $\boldsymbol{\Psi}_{1 h}$ are called the $h^{\text {th }}$ canonical coordinates, and the vectors $\lambda_{1 h}^{-1 / 2} \boldsymbol{\varphi}_{1 h}$ are called the $h^{\text {th }}$ dual canonical coordinates $[14,16]$.

In investigating the differences in trophic parameters between measuring series, the canonical variate analysis consists in transforming the matrix $\mathbf{C}_{2} \boldsymbol{\Xi}_{2}$ into a set of new variables. Following this transformation, this matrix is presented in the form:

$$
\mathbf{C}_{2} \boldsymbol{\Xi}_{2}=\sum_{h=1}^{b} \lambda_{2 h}^{-1 / 2} \boldsymbol{\psi}_{2 h} \boldsymbol{\varphi}_{2 h}^{\prime},
$$

where $b=\min (K, J-1)$ and the vectors $\boldsymbol{\Psi}_{2 h}, \boldsymbol{\varphi}_{2 h}$ and scalars $\lambda_{2 h}$ are determined and standardised as in the investigation of differences between experimental objects.

The same analysing procedures were used in case of trophic parameters and parts of reservoir.

\section{Results}

Results of canonical variates analysis based on comparison of selected physico-chemical parameters describing trophic level of the reservoir according to different experimental sites (site A surveyed in years 2012-2014, site B in years 2013-2014) were showed in Figure 2. According to localisation of experimental sites it was found, that results obtained in years 2012 and 2013 for site A were different from the rest of results. It was related mostly to the changes of parameters like $\mathrm{BOD}_{5}$ and concentrations of TOC, which were very high in the year 2012 (Table 1). Big variability of parameters in site A between years 2012 and 2013 was related to initial state of reservoir and potentially bigger agricultural pressure in that part of watershed, low water depth and thus low water volume in this part of reservoir. Part A of reservoir was fulfilled with water in the year 2004, that this part was functioning as a separate lake for several years till he summer 2012. In the 2013 situation changed due to removing of causeway and beginning of alignment of water level in both parts. It was the reason why results of trophic parameters from samples taken in 2013 were different from other years and were difficult to compare to other lakes.

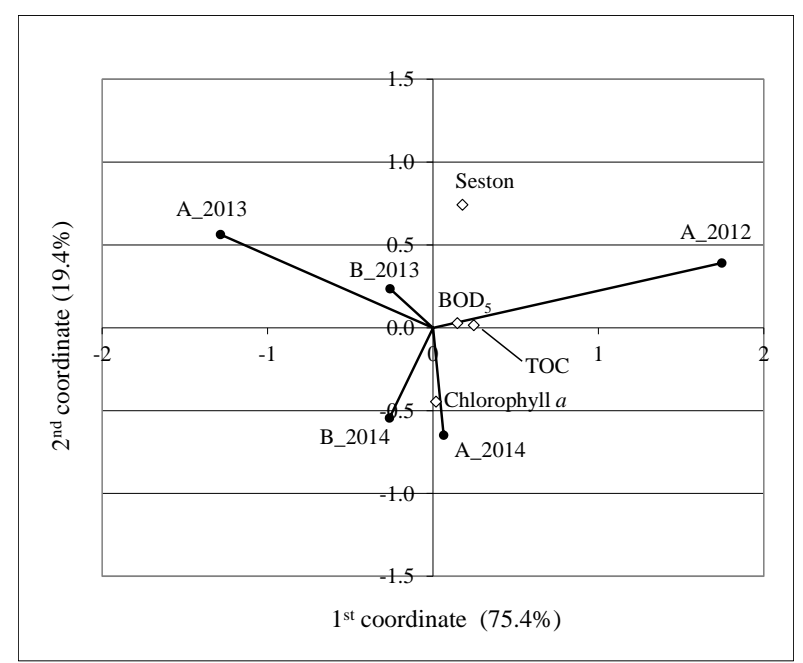

Fig. 2. Position of experimental objects determined by trophic elements in the space of the first two canonical variates and spacing of these parameters in the dual space.

Table 1. Differences of trophic elements between mean value in individual experimental object and the general mean $\left(\mathbf{C}_{1} \Xi_{1}\right)$.

\begin{tabular}{|c|c|c|c|c|}
\hline $\begin{array}{c}\text { Experimental } \\
\text { object }\end{array}$ & Chlorophyll $\boldsymbol{a}$ & Seston & TOC & BOD 5 \\
\hline A_2012 & -0.192 & 3.185 & 2.005 & 1.425 \\
\hline A_2013 & -0.092 & 1.235 & -1.620 & -0.738 \\
\hline A_2014 & 2.281 & -2.465 & 0.880 & -0.163 \\
\hline B_2013 & -2.892 & 0.010 & 0.130 & -0.463 \\
\hline B_2014 & 0.896 & -1.965 & -1.395 & -0.062 \\
\hline general mean & 10.823 & 5.509 & 15.231 & 2.414 \\
\hline
\end{tabular}

In the year 2014 part A and B of reservoir had similar trophic conditions and it's confirming stabilisation of the reservoir as an ecosystem. Water table level was also stable, thus low average water depth was not affected water quality [17-18]. Level of seston was high in part A in years 2012, 2013 and lower in the year 2014 in both parts of lake. In contrary, concentrations of chlorophyll $a$ were high in the year 2014 and lower in years 2012 and 2013.

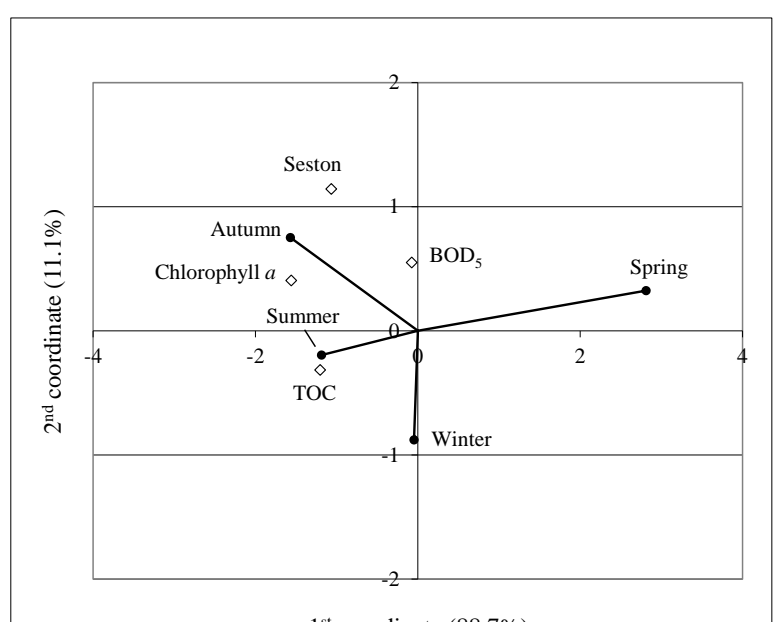

Fig. 3. Position of experimental objects determined by trophic elements in the space of the first two canonical variates and spacing of these parameters in the dual space. 
Analysis of CVA results presented in Figure 3 showed, that spring results were opposed to other seasons. Autumn and summer trophic characteristics were similar and had high concentrations of seston, chlorophyll $a$ and TOC, while at spring these values were low (Table 2). It was caused by natural processes occurred during spring season in water bodies when algal blooms are not present. During winter time lower values of $\mathrm{BOD}_{5}$, seston and chlorophyll were observed together with higher presence of TOC. The biochemical oxygen demand was average in summer and spring, high during autumn and low in winter period. Increase of $\mathrm{BOD}_{5}$ in autumn is generally related to phytoplankton decomposition after vegetation season and usage of oxygen in organic matter decay. Analysing of CVA results (Figure 4) it was found, that site $\mathrm{A}$ in years 2012 and 2013 and both lake sites in year 2014 are close to each other. It confirm, that after connection of both parts and fulfilling with water, studied reservoir was functioning as a complete lake. In years 2012 and 2013 part A of reservoir was characterised with high concentrations of nitrates and low concentrations of ammonium in comparison to year 2014 in both parts of rebuilt lake (Table 3).

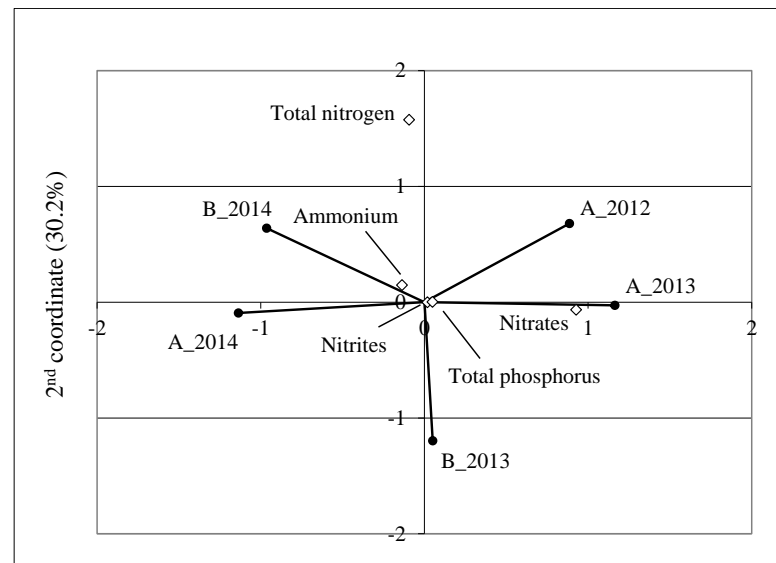

$1^{\text {st }}$ coordinate $(56.9 \%)$

Fig. 4. Position of measuring series determined by chemical parameters in the space of the first two canonical variates and spacing of these parameters in the dual space.

Table 2. Differences in concentration of trophic elements between mean value for year season and the general mean $\left(\mathbf{C}_{2} \Xi_{2}\right)$.

\begin{tabular}{|c|c|c|c|c|}
\hline $\begin{array}{c}\text { Year } \\
\text { season }\end{array}$ & $\begin{array}{c}\text { Chlorophyll } \\
\boldsymbol{a}\end{array}$ & Seston & TOC & BOD $_{\mathbf{5}}$ \\
\hline Winter & -0.777 & -2.095 & 0.830 & -0.983 \\
\hline Spring & -8.455 & -5.215 & -6.990 & -0.063 \\
\hline Summer & 3.903 & 2.405 & 2.730 & 0.007 \\
\hline Autumn & 5.329 & 4.905 & 3.430 & 1.038 \\
\hline
\end{tabular}

It was also observed, that total nitrogen was high in part A (2012) and B (2014), whilst low in part B in the year 2013. The concentrations of nitrites and total phosphorus were not affected variability of experimental objects. In part A of lake the impact of surrounding arable lands was probable source of nitrogen. Situation has changed when connection of both parts was made and thus increase water volume together with changes of watershed structure by forests surrounding part B were key factors in determining of trophic conditions.

Table 3. Differences of chemical parameters in individual experimental object and the general mean.

\begin{tabular}{|c|c|c|c|}
\hline $\begin{array}{c}\text { Experimental } \\
\text { object }\end{array}$ & Ammonium & Nitrites & Nitrates \\
\hline A_2012 & 0.020 & 0.016 & 0.305 \\
\hline A_2013 & -0.111 & 0.002 & 0.665 \\
\hline A_2014 & 0.080 & -0.011 & -0.416 \\
\hline B_2013 & -0.083 & 0.006 & -0.026 \\
\hline B_2014 & 0.094 & -0.013 & -0.528 \\
\hline general mean & 0.153 & 0.017 & 0.477 \\
\hline $\begin{array}{c}\text { Experimental } \\
\text { object }\end{array}$ & Total phosphorus & Total nitrogen \\
\hline A_2012 & 0.030 & \multicolumn{2}{|c|}{0.714} \\
\hline A_2013 & 0.018 & \multicolumn{2}{|c|}{-0.344} \\
\hline A_2014 & -0.033 & \multicolumn{2}{|c|}{-0.122} \\
\hline B_2013 & 0.007 & \multicolumn{2}{|c|}{-0.802} \\
\hline B_2014 & -0.023 & \multicolumn{2}{|c|}{0.554} \\
\hline general mean & 0.054 & \multicolumn{2}{|c|}{1.535} \\
\hline
\end{tabular}

Analysing of the CVA results presented in Figure 5 it was found, that sites can be considered in two groups, summer and autumn, spring and winter and both pairs significantly differs. During summer and autumn the concentration of total nitrogen was high, while nitrates and ammonium were low. Values of total phosphorus and nitrites were similar in all seasons. During winter and spring times the concentration of nitrates and ammonium were high and total nitrogen was low in relation to summer and autumn. High level of mineral forms of nitrogen in waters during winter-spring period is related to its migration from watershed, release from organic matter decomposition in sediments and simultaneously, smaller primary production.

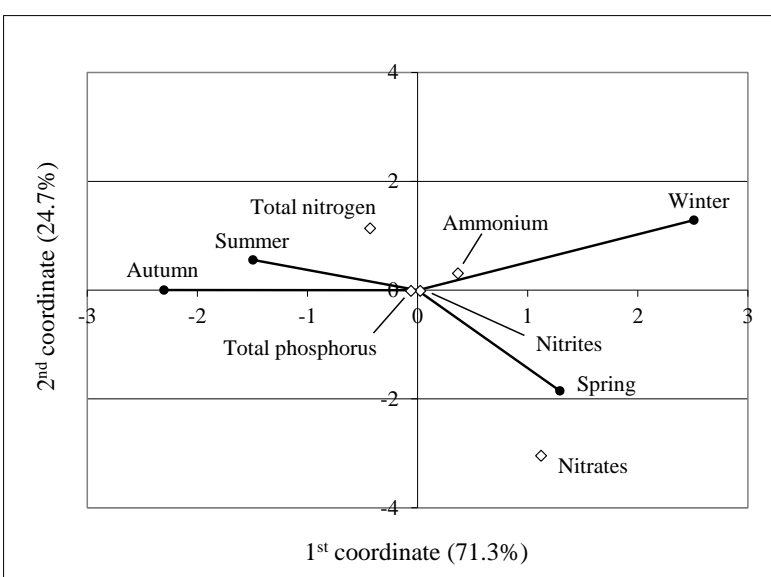

Fig. 5. Position of experimental objects determined by chemical parameters in the space of the first two canonical variates and spacing of these parameters in the dual space. 
Table 4. Differences of chemical parameters between mean value for year season and the general mean.

\begin{tabular}{|c|c|c|c|}
\hline $\begin{array}{c}\text { Year } \\
\text { season }\end{array}$ & Ammonium & Nitrites & Nitrates \\
\hline Winter & 0.275 & 0.010 & -0.231 \\
\hline Spring & -0.024 & 0.011 & 1.421 \\
\hline Summer & -0.122 & -0.016 & -0.641 \\
\hline Autumn & -0.130 & -0.005 & -0.549 \\
\hline $\begin{array}{c}\text { Year } \\
\text { season }\end{array}$ & Total phosphorus & Total nitrogen \\
\hline Winter & -0.023 & \multicolumn{2}{|c|}{0.192} \\
\hline Spring & -0.015 & \multicolumn{2}{|c|}{-0.585} \\
\hline Summer & -0.023 & \multicolumn{2}{|c|}{-0.193} \\
\hline Autumn & 0.061 & \multicolumn{2}{|c}{0.585} \\
\hline
\end{tabular}

\section{Discussion}

It has been shown how useful the canonical decomposition of $\mathbf{C}_{1} \boldsymbol{\Xi}_{1}$ can be in analysing and visualising the empirical departure from differences in trophic parameters. Studied reservoir is unique and there is no analogous object to compare but in rural landscape of central Poland ponds appeared after excavation of peat are present. Generally, they have clean mesotrophic waters with presence of rare algae from a genus of green algae referred to charophytes but as all water bodies situated in rural landscape they can have sporadic or frequent contact with nutrients from watershed or point sources $[19,20]$. The water area of studied reservoir is equal to 10.71 ha and such a small reservoir is especially susceptible for degradation [21]. Additionally, the rate of evaporation from square meter is about $30 \%$ higher than in case of bigger lakes, thus they can functioning only in areas with appropriate water conditions [22], which are present in Nienawiszcz watershed. To maintain good water quality in post peat lakes excavation of peat to the mineral substrate is necessary to avoid resuspension of organic matter in suitable physico-chemical conditions or during water mixing, which in shallow water bodies occur during wind conditions [23, 24], thus peat material was removed from the reservoir bottom. Water trophy of small and shallow reservoirs is higher than in other types of lakes under similar watershed and climate conditions and both former and recent studies confirm this phenomenon $[25,26]$. In case of Nienawiszcz reservoir trophic parameters were changing during year and i.e. presence of mineral forms of nitrogen in waters during winter-spring period was related to impact of watershed and surrounding agricultural areas.

The analysis of biplot based on design matrix $\mathbf{X}$ and matrix $\mathbf{C}$ represented a set of contrasts between the rows of $\mathbf{X}$, presenting the differences of trophic parameters taking into account variability related to experimental object and time of sampling. Use of CCA method enable to graphically extent interpretation of results obtained during experiment in case when observations are classified according to experimental factors. In another paper [27] positions of the pathogen isolates were presented graphically according to their differences in accumulation of reactive oxygen for data set undergoing one-way classification. In two years of studies on differences in visible tobacco leaf injury the use of CCA gave opportunity to arrange experimental objects according to rural and urban sites [28]. Similar results were found in case of analyses of sunflower strains, which were compared in a field experiment organised as an incomplete block design [13] and in analysis of with winter wheat at several places using repeated series of experiments [29]. Canonical variate analysis can be applied to other kinds of date matrix, like a matrix of one-way classification, a matrix of interactions, etc. However, to achieve such a decomposition the proper choice of a matrix norm is necessary, first to measure a total variation and second to derive the corresponding canonical approximations [13]. Presented experiments based on the normalisation of canonical coordinates to corresponding eigenvalues. Modification of matrix norm caused change of the position of selected experimental objects in the space of the two first canonical variates. When reducing of the representation to the first two axes only, one obtains an approximations of the matrix $\mathbf{C}_{1} \boldsymbol{\Xi}_{1}$, which can be then displayed by a biplot comparable to principal component analysis. Principal component analysis in studies on the dynamics of variation in the microbial composition of soil and dehydrogenase activity, was used to visualise multidimensional dependences between soil bioactivity, fertilisation methods, and conditions of analyses [30]. In these analysis the orthogonal transformation of observed variables to a new set of non-correlated components was performed. The principal component analysis in contrary to CCA based on object-oriented averages and on the correlation matrix. Additionally, the additive main effects and multiplicative interaction model is another approach to evaluate results from experiments of analysing of yieldtrial data, where image of experimental objects in two dimensional biplot is obtaining [31]. For instance, results presented for genotype $\times$ environment interaction [32] gave possibility of similar interpretation as in CCA [29].

\section{Conclusions}

Described studies indicate, that canonical variates appears to be an appropriate technique for presentation differences between parts of reservoir and measuring series. The analysis allowed to formulate following conclusions:

1. According to trophic parameters the biggest difference was in case of part A of reservoir between years 2012 and 2013. In the year 2014 parts A and B were connected and reservoir began to stabilise as one ecosystem.

2. Values of trophic parameters measured at spring were different that in other measurement series.

3. Changes of nitrates and total nitrogen concentrations affected the variability of experimental objects stronger, then concentrations of nitrites and total phosphorus. 


\section{Acknowledgement}

Studies were financed by private investor Przemysław Frankowski, PhD.

\section{References}

1. M. Szwed, G. Karg, I. Pińskwar, M. Radziejewski, D. Graczyk, A. Kędziora, Z.W. Kundzewicz, Nat. Hazards Earth Syst. Sci. 10, 1725 (2010)

2. I.S. Cohen, M.A.I. Ibarra, G.E. Arriaga, J.C. Paredes, M.A.V. Valle, P.B. Hurtado, W.O. Bustamante, Meteorol. Hydrol. Water Manage. 6(2), 59 (2018)

3. R. Gamrat, Int Agrophys 20(2), 97 (2006)

4. W. Majewski, Meteorol. Hydrol. Water Manage. 1(1), 33 (2013)

5. T. Joniak, N. Kuczyńska-Kippen, M. Gąbka, Hydrobiologia 793(1), 121 (2017)

6. Directive 2000/60/EC of the European Parliament and of the Council of 23 October 2000 establishing a framework for Community action in the field of water policy

7. W. Mioduszewski, E.P. Querner, Z. Kowalewski, J. Water Land Dev. 23 (X-XII), 41 (2014)

8. Project of counteraction against consequences of drought in upper Vistula water region 2015 (RZGW, Kraków) [in Polish]

9. A. Kowalska, Interdisciplinar problems in mining and geology (Oficyna Wydawnicza Politechniki Wrocławskiej, Wrocław, 141, 2010) [in Polish]

10. R. Gołdyn, Role of water reservoirs in agricultural landscape (Fundacja Biblioteka Ekologiczna, Poznań, 162, 2012) [in Polish]

11. K. Sobczyńska-Wójcik, Protection of reserves and water quality in rural landscape (Uniwersytet Warmińsko-Mazurski, Olsztyn, 197，2010) [in Polish]

12. P. Frankowski, Studia Lednickie. 12, 63 (2013) [in Polish]

13. M. Lejeune, T. Caliński, J. Multivariate Anal. 72, $100(2000)$

14. D. Kayzer, K. Borowiak, A. Budka, J. Zbierska, Environmetrics 20, 666 (2009)

15. A. Budka, K. Borowiak, J. Zbierska, D. Kayzer, Fresenius Envir. Bull. 20(4), 969 (2011)

16. D. Kayzer, A. Budka, K. Borowiak, J. Zbierska, M. Lisiak, Biom. Lett. 52(1), 23 (2015)
17. P. Nõges, T. Nõges, L. Tuvikene, H. Smal, S. Ligeza, R. Kornijów, W. Peczula, E. Becares, F. Garcia-Criado, C. Alvarez-Carrera, C. Fernandez-Alaez, C. Ferriol, R.M. Miracle, E. Vicente, S. Romo, E. van Donk, W. van de Bund, M. Nykanen, E. de Eyto, K. Irvine, D. Stephen, S. Collings, B. Moss, Hydrobiologia 51, 506 (2003)

18. R. Staniszewski, J. Szoszkiewicz, J. Elem. 15(4), 705 (2010)

19. W. Mioduszewski, J. Water Land Dev. 26(VII-IX), 65 (2015)

20. P. Mróz, M. Gąbka, Bot. Stec. 17, 71 (2013)

21. D. Kudelska, D. Cydzik, H. Soszka, Principles of basic monitoring of lakes (Państwowa Inspekcja Ochrony Środowiska, Warszawa 42, 1994) [in Polish]

22. A. Kędziora, L. Ryszkowski, C. Przybyla, Water management in Wielkopolska (Abrys, Poznań, 16, 2005) [in Polish]

23. A. Karwacka, P. Niedzielski, R. Staniszewski, Rocz. Ochr. Sr. 17, 1684 (2015)

24. E.G. Chung, F.A. Bombardelli, S.G. Schladow, Water Resour. Res. 45, 1 (2009)

25. A. Pasztalaniec, M. Poniewozik, Limnologica 40(3), 251, (2010)

26. J. Padisák, G. Borics, G. Fehér, I. Grigorszky, I. Oldal, A. Schmidt, Z. Zámbóné-Doma, Hydrobiologia 502, 157 (2003)

27. J. Mucha, A. Budka, D. Kayzer, M. Guzicka, P. Łakomy, M. Zadworny, Eur. J. Plant Pathol. 143, 277 (2015)

28. A. Budka, D. Kayzer, K. Borowiak, J. Zbierska, A. Wolna-Maruwka, A. Schroeter-Zakrzewska, A. Chlebowska Arch. Environ. Prot. 40(4), 53 (2014)

29. T. Caliński, S. Czajka, Z. Kaczmarek, Cultivar Testing Bulletin 12(17/18), 7 (1987)

30. A. Niewiadomska, H. Sulewska, A. WolnaMaruwka, K. Ratajczak, K. Głuchowska, Z. Waraczewska, A. Budka, Pol. J. Environ. Stud. 27(6), 2687 (2018)

31. H.G. Gauch, H.P. Piepho, P. Annicchiarico, Crop Sci. 48, 866 (2008)

32. A.C. Neisse, J.L. Kirch, K. Hongyu, Biom. Lett. (to be published) 